\section{CONTRAPUNTEOS DE LYDIA CABRERA}

\author{
Carmen Ortiz García \\ Consejo Superior de Investigaciones Científicas \\ ORCID iD: https://orcid.org/0000-0002-8978-0650 \\ Carmen.ortiz@cchs.csic.es
}

Cómo citar este artículo/Citation: Ortiz García, C. (2020). Contrapunteos de Lydia Cabrera. Arbor, 196 (796): a559. https://doi.org/10.3989/arbor.2020.796n2012

Recibido: 17 diciembre 2019. Aceptado: 21 febrero 2020.

RESUMEN: Todavía hoy en la historia de la antropología cubana se presta poca atención a la escritora y antropóloga Lydia Cabrera, quien solo muy recientemente ha empezado a formar parte de la nómina intelectual de la cultura cubana oficial. Sin embargo, en función de su obra y trayectoria vital puede considerarse a Cabrera como la fundadora moderna de los estudios sobre las religiones afrocubanas.

El objeto central de este texto es analizar el trabajo etnográfico de Lydia Cabrera a partir de la idea de que existe un contrapunteo, un diálogo, un juego metafórico, entre la identidad liminar de la propia autora -manifiesta en un sentido racial, cultural, de género, social y político- y su interés y dedicación a la aportación de los esclavos y la población de origen africano a la historia, a la cultura y, en última instancia, a la identidad misma de su patria cubana.

PALABRAS CLAVE: Cuba; folklore; religiones afrocubanas; género; Fernando Ortiz.

\section{LYDIA CABRERA COUNTERPOINTS}

Copyright: (C) 2020 CSIC. Este es un artículo de acceso abierto distribuido bajo los términos de la licencia de uso y distribución Creative Commons Reconocimiento 4.0 Internacional (CC BY 4.0).

ABSTRACT: Even today in the history of Cuban anthropology, little attention is paid to the writer and anthropologist Lydia Cabrera, who has only recently begun to be part of the list of intellectuals in official Cuban culture. However, because of her work and life trajectory, Cabrera can be considered the modern founder of studies on Afro-Cuban religions.

The main purpose of this text is to analyse Lydia Cabrera's ethnographic work based on the idea that there was a 'counterpoint', a dialogue, a metaphorical game, between the liminal identity of the author herself - manifested in a racial, cultural, gender, social and political sense - and her interest and dedication to the contribution of slaves and the population of African origin to the history, culture and, ultimately, the identity of their Cuban homeland.

KEYWORDS: Cuba; folklore; Afro-Cuban religions; gender; Fernando Ortiz. 
En cualquier panteón que se precie los dioses o los espíritus son muchos y están ordenados según complejas clasificaciones. Así encontramos que en la trinidad de los estudios culturales afrocubanos, que enunció Jorge Castellanos en 2003, aparece Lydia Cabrera como si de una Yemayá se tratara; flanqueada por dos varones. No hay porqué discutir la preeminencia de Fernando Ortiz en este panteón; sus obras numerosas son bien conocidas y respetadas. Tal vez menos conocida es la figura de Rómulo Lachatañeré o Lachataignerais Crombet (1909-1952), discípulo y crítico a la vez de Ortiz, que llevó a cabo el primer intento de clasificación de los orígenes étnicos de los cultos afrocubanos. Igual que Lydia Cabrera, Lachatañeré, que como ella no llegará a profesionalizarse ni a formar parte de la comunidad académica en su corta vida (Barreal, 1992; López, 2012), se ocupó de las leyendas y el folklore para centrarse luego en el asunto central de la religión. Cabrera, igual que Ortiz, no olvida nunca la íntima relación de la expresión musical con el ritual en los cultos afrocubanos.

La trascendencia de Fernando Ortiz para la antropología anglosajona estuvo en buena medida determinada por la aceptación por parte de una de sus mayores estrellas, Bronislaw Malinowski, del concepto de transculturación propuesto en 1940 por Ortiz en su libro más influyente (Ortiz, 1940, pp. 98-104; Le Riverend, 1991). Pero en este, sin embargo, hay otro concepto que a la larga ha resultado igualmente fértil en el pensamiento antropológico y para los estudios culturales. Me refiero al término "contrapunteo" que es el que aparece precisamente en el título de la obra: Contrapunteo cubano del tabaco y el azúcar, y que sería la manera de abordar cómo los fenómenos de transculturación (concretamente de hibridación blanquinegra) tuvieron lugar en Cuba: en forma de contrapunteo o contrapunto.

Este término y este concepto es el que ha sido discutido y valorado precisamente por la crítica postmoderna, superando el clásico marchamo de la obra de Ortiz como una investigación decimonónica y positivista que poco tendría que aportar a los actuales estudios sociales (sobre esto véase, por ejemplo, el examen crítico que le dedica Benítez Rojo, 1989, pp. 149-185; y más recientemente el libro de Santí, 2002).

El término contrapunteo es un cubanismo de contrapunto (véase el Diccionario de la Real Academia Española), un concepto fundamentalmente musical que tiene que ver con el ritmo y las armonías en ciertas composiciones musicales que funcionan de un modo preciso, dialogando y contraponiéndose voces diferentes en un tempo determinado. Entre ellas, una de las más famosas es la "fuga", que está conformada por una melodía que se inicia, a la que replica una segunda, en un distinto registro o con el ritmo melódico ligeramente diferente; las dos se superponen formando una composición entera y a su vez distinta a sus dos (y sucesivas) partes componentes. En los diccionarios se recoge también que el contrapunteo es una forma de arte popular en que dos intérpretes improvisan sones sobre un mismo tema contraponiéndose y contestándose. Es un género popular en Cuba y también en Colombia y Venezuela, donde es famoso el contrapunteo llanero o del llano, y en otras partes del mundo cultural hispánico. Sus letras suelen ser humorísticas y muchas veces pícaras. Finalmente, la contraposición que implica el concepto aparece en una tercera acepción del término que es la de picarse o resentirse dos personas.

Como se ha mencionado antes, varios ensayos han abordado el contrapunteo cubano del tabaco y el azúcar de Fernando Ortiz desde la crítica literaria (Benítez Rojo, 1989; Benítez Rojo, 2003 y Santí, 2002), la epistemología (Zalamea, 2000, p. 166) y el conocimiento de la composición musical (Zaramella, 2014). Algunos otros críticos, como Edna M. Rodriguez-Mangual (2004) en su difundido e imprescindible libro sobre Lydia Cabrera, han utilizado además a Fernando Ortiz en un análisis basado en la oposición o contradicción de su visión de la cultura negra respecto a la aportación de los trabajos de Lydia Cabrera. Como han señalado algunos reseñadores del libro de RodriguezMangual (Duany 2005; Pérez, 2006), no es necesario ni productivo anular o desacreditar la obra afrocubana de Fernando Ortiz, por patriarcal y acomodaticia, para valorar en toda su diferencia, originalidad y categoría intelectual la de Lydia Cabrera. Así, es difícil coincidir con Rodríguez-Mangual en que la perspectiva de Ortiz acerca de la cultura afrocubana sea impostada (Rodriguez-Mangual, 2004, pp. 40 y ss.), y más fácil, en cambio, apreciar la capacidad humorística e irónica que tanto él como Cabrera atesoraban y la confluencia de ambos en algunos otros terrenos. Más bien entre ellos podría decirse que se produce un contrapunteo; una lucha poética improvisada, que no llega en ningún caso, desde mi punto de vista, a poder considerarse como una contradicción o antítesis, sino como un juego librado en distintos planos de ritmo.

Es conocida la opinión de Guillermo Cabrera Infante acerca de la rivalidad personal existente entre Ortiz y Cabrera, apreciable según él en la primera frase del "presuntuoso" prólogo -curiosamente titu- 
lado "Prejuicio"- que el primero hiciera a la edición en castellano de los Cuentos Negros de Cabrera en 1940, en que se arroga la preeminencia de haber "iniciado" a la autora en el interés por la cultura de los afrocubanos y sus expresiones literarias. Según Cabrera Infante se trataría de un gusto muy anterior, ya que provenía ni más ni menos que de las tatas que habían cuidado a Lydia cuando niña (Cabrera Infante, 1996). Es evidente que los dos prólogos a los Cuentos negros de Ortiz y Cabrera Infante son radicalmente distintos, y mucho más sensible y literario el del segundo (sin parentesco biológico con Lydia), que el algo envarado del erudito cuñado de la autora. Pero tal vez el desencuentro que parece que se trasluce en el texto podría juzgarse de un modo más acorde con el carácter irónico y humorístico de ambos personajes como un contrapunteo; una pugna poética y de palabras en que los dos intérpretes valoran y se contraponen al contrario a partir de sus composiciones, que son, a su vez, el motivo y el inicio para crear la propia como contestación dialogada, y a partir de ella afirmarse cada uno en sí mismo. Así, puede ser que la joven Lydia Cabrera fuera la acompañante de Fernando Ortiz en la observación de sus primeras ceremonias, pero el posterior desarrollo de su literatura y su antropología, su "antropoesía" (Cabrera Infante, 1996), fue desde luego algo muy diferente y en varios sentidos superadora de los conceptos y la obra de Ortiz. La opinión de la protagonista sobre la atribución de Ortiz de ser el guía para sus primeros contactos con los afrocubanos quedó reflejada en el libro que Rosario Hiriart dedicó a Lydia Cabera, recogiendo las entrevistas mantenidas con ella:

“No, Fernando no me llevó a estos estudios. Déjame decirte que a Fernando Ortiz, que era mi cuñado, yo lo quería mucho y lo recuerdo con gran cariño [...] Te repito: fue en París donde empezó a interesarme África" (Hiriart, 1983, pp. 73-74).

Algunos datos objetivos ahondan en esta relación, no exactamente discipular, pero sí muy estrecha en lo personal e intelectual, que comienza en el propio ámbito familiar ya que Fernando Ortiz, de frecuentador del círculo amistoso del abogado Raimundo Cabrera, pasó a formar parte de la familia de la niña Lydia, al casarse en 1908 con su hermana Esther. Lydia aparece luego con su cuñado en la fundación de la Sociedad de Folklore Cubano en 1923 y acompañándole ya en 1927-28 en sus incursiones a los bembés de los barrios de La Habana a los que acudía para documentarse sobre la música y los ceremoniales afrocubanos. Pero también a través de Ortiz -en realidad formando par- te del mismo círculo de sociabilidad e intelectualidad de la burguesía cubana "blanca", que incluía también numerosas conexiones europeas y norteamericanas-, Lydia entra en relación con José María Chacón y Calvo (Guillama Camba, 2019), en cuya casa de Madrid en 1926 conoce a Federico García Lorca -que dedicará a Lydia Cabrera y a su "negrita" (Carmela Bejarano) su poema “La Casada Infiel" (Hiriart, 1983, pp. 154-155)-, y después con otros intelectuales y artistas españoles que serían traídos a Cuba por Ortiz y la Sociedad Hispano-Cubana que él promovió (del Toro, 1996; PuigSamper y Naranjo, 2001). Finalmente, la publicación primera del material que conformará su gran obra EI Monte (1954) tendrá lugar en la revista de la Sociedad de Estudios Afrocubanos, fundada y dirigida por Ortiz.

De hecho, podría hablarse de que en estas décadas de 1920 y 30 había una cierta moda de llevar a los extranjeros a los bembés, como una atracción exótica y folklórica; lógicamente en relación con la fascinación estética que lo africano causaba en las vanguardias artísticas europeas. Así, Lydia recordaba la impresión fuerte que sufrió García Lorca cuando le llevó a una ceremonia de ñáñigos (García Vega, 1993, p. 48), y, como ejemplo, puede recordarse también la reseña que publicó la revista Carteles (no 7, La Habana, 13 de febrero de 1927, pp. 12-13) de la visita a una sesión de música afrocubana, organizada para el intelectual español Fernando de los Ríos invitado por la HispanoCubana, que estuvo acompañado por Fernando Ortiz, Alejo Carpentier, Amadeo Roldán y Lydia Cabrera.

Así pues, Cabrera y Ortiz formaban parte de un mismo ambiente familiar y socio-cultural, en el cual todavía en ese momento era excepcional que se prestara atención a las formas de vida y características de las poblaciones de procedencia africana, a las que ambos dedicaron su trabajo intelectual. Sin embargo, sus respectivas obras son claramente contrapuntísticas: positivista, normativa, científica, claramente hegemónica, masculina y sujeta a las normas formales de la investigación social, la de Ortiz; artística, literaria, creativa, polifónica, subalterna, no académica y femenina, la de Cabrera.

Isabel Castellanos, quien no solo conoció su obra de creación e investigación, sino que convivió con ella en la última etapa de su vida, nos dice:

"Lydia no tenía ningún interés académico, absolutamente ninguno; ella era una artista, ella entraba desde otro punto de vista. Don Fernando era el científico, pero Lydia es una artista, también por la capacidad de empatía que ella tenía con la gente, con sus 
informantes. Lo que a ella le interesaba, a ella lo que le interesa es simplemente ser el canal, mira, no hay escritor que yo haya conocido, más despegado de su obra que Lydia Cabrera, era una persona que de verdad no le interesaba ni ser famosa ni ser reconocida, absolutamente nada, no le interesaba lo que la gente dijera de ella, no le interesaba o sea toda esa cuestión de celos, toda esa cosa del mundo, no hay nada más completamente ajeno a ella" (Cámara, 2015, p. 29).

Pero, además de la veracidad de este testimonio, hay en la propia obra de Cabrera la constatación de un tipo de autoría, en la que la investigadora se reivindica como "canal" o simple transmisora de las voces y los conocimientos expertos de sus informantes y colaboradores (Cairo, 2002, p. 82; Cámara, 2004-2005, p. 248). La manera de transcribir los lenguajes, ritmos y conocimientos religiosos de los afrocubanos, original y característica de Lydia Cabrera, es muy diferente del sentido autorial, basado en los principios de autoridad de las disciplinas sociales y sometido a los modos académicos, que caracterizaba la metodología y la obra de Fernando Ortiz.

Por otro lado, si la relación entre ambos antropólogos puede verse como un diálogo contrapuntístico, también este tropo, esta metáfora (pues, aunque se hable de un método de documentación y análisis, no deja de tratarse de una metáfora), puede servir para exponer la imbricación íntima entre la vida, las identidades cruzadas de Lydia Cabrera y su propia obra.

La primera de estas aparentes contradicciones es la de la identidad étnica. Lydia Cabrera era "blanquísima", es decir, nacida en una familia cubana de la élite intelectual, sin mucho color por medio. Sin embargo, como etnógrafa fue aceptada y reconocida como parte de su comunidad por muchos grupos de negros, que contaban incluso entre ellos con hijos de esclavizados africanos, y que conformaban comunidades religiosas, algunas más abiertas, como la santería, pero otras más secretas y clandestinas como las de las Reglas Abakuá y del Palo Monte, entre las cuales, la "blanquitud" no era bien considerada ni admitida entonces en rituales y actividades esotéricas. Lydia, la niña pequeña y mimada de don Raimundo Cabrera, abogado y periodista, un intelectual de la generación del 98, una mundele (mujer blanca) de clase alta, era en realidad "blanquinegra", una amiga de los hijos de los esclavos. En palabras de Cabrera Infante, "De Lydia Cabrera se puede decir que es la señora blanca con tatuajes negros por toda su escritura" (Cabrera Infante, 1996).
Es bien conocido por las biografías y entrevistas con ella que debemos a Rosario Hiriart (1983), Isabel Castellanos y Josefina Inclán (1987), Mariela Gutiérrez (1991) y otras que el primer contacto de Cabrera con la parte afrocubana de su mundo tuvo lugar en el propio ámbito familiar. Como era normal en las familias burguesas y pudientes, las negras y los negros formaban parte como sirvientes de la unidad doméstica y la relación con todos los miembros de la familia y especialmente con los niños era estrecha. Dos de las informantes principales de Cabrera, Teresa Muñoz (Omi-Tomí) (Hiriart, 1983, p. 6; Sánchez Morales, 2016, p. 39) y Calixta Morales (Oddeddei) proceden de esta infancia y ambiente doméstico. Lydia Cabrera alude muchas veces a este trato íntimo:

"Y en cuanto a los negritos, a pesar de que tenía en mi familia el antecedente de mi cuñado, el investigador Fernando Ortiz, ellos eran algo fuera de lo que me interesaba. Pero en París cambié respecto a ellos [...] Empecé a recordar que cuando yo era chiquita existió una Tata Tula que me dormía rascándome la planta del pie. Recordé que oía a los criados en el fondo de la casa. También en un año en que volví a La Habana para ver a mi madre, estuve con la viejita Omí Tomí, que había sido costurera de mi abuela" (García Vega, 1993, p. 45).

Tal relación ya fue identificada y valorada por María Zambrano en el artículo que dedicó a Lydia Cabrera: "Tuvo que ir muy lejos porque ha tenido que adentrarse en su infancia. La raza de piel oscura es la nodriza verdadera de la blanca, de todos los blancos en sentido legendario" (Zambrano, 1950, pp. 11-15).

Los negros, no obstante, fueron re-descubiertos por la joven pintora Lydia Cabrera al otro lado del Atlántico. En sus propias palabras: "había descubierto Cuba a orillas del Sena" (Hiriart, 1983, p. 23). Si el regreso a su infancia fue necesario, igualmente lo fue primero el extrañamiento de abandonar su isla para irse a vivir a París en 1927 -aunque su primer viaje a Europa, también con su madre, se había producido ya en 1905. La joven con inquietudes artísticas e interesada en el arte oriental conectará en París con el movimiento de la negritud, sus escritores y publicistas, y no tanto con el negrismo -es decir, la moda o influencia del arte y las culturas africanas en los artistas visuales de vanguardia.

En París se reencontró con la que sería su primera compañera, la escritora venezolana Teresa de la Parra, a quien había conocido en La Habana en un congreso literario organizado en 1924 (Hiriart, 1980). A través de los ojos de Teresa de la Parra, Lydia enfoca de nuevo sus recuerdos negros. El contraste, la casi infran- 
queable distancia existente entre dos señoras de maneras elegantes, con inquietudes y talentos evidentes, de refinada cultura europea, residentes en París, y sus sirvientes, viejos descendientes de esclavos africanos, será precisamente el ámbito, el espacio liminar donde va a situarse Lydia Cabrera; en ese contrapunteo blanquinegro va a vivir y crear a partir de entonces. Con Teresa de la Parra, una mujer cosmopolita y escritora ya consagrada, a quien llevará también a los barrios negros de La Habana, desarrollará por primera vez una identidad personal libre y gracias a ella escribirá su primer y famosísimo libro, los Cuentos Negros de Cuba, publicado en francés en 1936 y luego en español, en La Habana, en 1940.

Los veintidós cuentos negros fueron escritos por Lydia durante el acompañamiento de la enfermedad que acabó en abril de 1936 con la vida de Teresa de la Parra en Madrid. Presintiendo la guerra europea Cabrera vuelve a Cuba, donde durante más de veinte años se dedicará con ahínco a la documentación etnográfica de la parte más íntima y profunda de la raíz transculturada por los negros esclavos en Cuba, la religión. Como recuerda Cabrera Infante (1996): “De no haber habido negros allá nunca habría vuelto a Cuba".

Los años centrales de su vida, los que transcurren entre 1940 y 1960, son los fundamentales en lo que tiene que ver con su trabajo etnográfico. Con su compañera, la archivera e historiógrafa María Teresa de Rojas, instaladas en la quinta de la familia de esta en Marianao, en La Habana, Cabrera desarrollará un intenso trabajo de campo, utilizando las "fuentes vivas" de los descendientes de esclavos, los únicos que para ella contaban con la suficiente autoridad y legitimidad para documentar su rasgo sociocultural e identitario más profundo y característico: su mundo religioso.

La identidad étnica de Lydia Cabrera resulta contrapuntística con su obra escrita, literaria y científica, en el sentido del contraste que encierra el que una mujer blanca de su tiempo, enculturada en el canon occidental, conservadora ideológicamente y sin estudios universitarios sea precisamente la autora de un acercamiento no solamente auténtico en lo que tiene que ver con el respeto a los propios códigos de conducta y creencias de un grupo claramente marcado y estigmatizado como un "otro" inasumible, sino que además esta obra suya sea aceptada como tal conocimiento participativo, tanto por los propios practicantes de las religiones afrocubanas que documentó, como por los expertos y especialistas en antropología religiosa que acabarán reconociéndola como una autoridad en el estudio de los cultos sincretizados afroamericanos.
La liminalidad social, política, racial de Lydia Cabrera es a mi juicio uno de los elementos que contribuyen a que su obra tenga un carácter reconocible de originalidad, como traslación escrita de un mundo de creencias comprendido y compartido. Su libro fundamental, El Monte, es así, no solo una obra considerada central para los antropólogos especializados en religión o que trabajan en esa parte del mundo. El Monte, un libro eminentemente dialógico y en ese sentido contrapuntístico, es sobre todo considerado una "biblia" para los iniciados y adeptos de la santería; una obra que ha tenido una vida subterránea y de la que han surgido múltiples otros libros, escritos, pero también tradiciones de transmisión oral, como brotes de una primigenia raíz (Dianteill y Swearingen, 2003).

Otro de los aspectos destacables en la biografía de Lydia Cabrera es su sororidad (Lagarde y de los Ríos, 2006). La práctica de una identidad de género femenina ha sido vista por algunas críticas de su obra como un elemento básico en su atención y dedicación a la cultura y la religión de los afrocubanos (Rodriguez-Mangual, 2004; Sánchez Morales, 2016). Su homosexualidad, vivida y asumida en un ámbito privado, pero también juzgada como una "otredad" por la sociedad burguesa y blanca a la que pertenecía, está en el fondo de su identificación con los esclavizados y excluidos por motivo de su raza. Por otro lado, esa "otredad" podía estar en el fondo de su aceptación por babalawos y creyentes religiosos como los abakuás que, sin compartir ni su identidad racial, ni tampoco la sexual -que no podía ser consentida en su mundo creencial- la admitieron entre ellos e incluso le habrían permitido el acceso a los elementos más esotéricos y secretos de sus espacios rituales. Si el viaje geográfico, el extrañamiento parisino, fue necesario para que Lydia Cabrera encontrara a sus negros. Este viaje fue también fundamental para permitirle una vida sentimental en la que las relaciones con sus mujeres han quedado, no obstante, o bien ocultadas por un silencio memorial, en el que tuvieron parte las mismas protagonistas (Sánchez Morales, 2016, p. 258), o bien subsumidas mediante la clasificación estereotipada como amigas por el dominio de un canon que no se entendía más que de un modo patriarcal y homofóbico (Sánchez Morales, 2016, pp. 56-90). En el mundo de relaciones femeninas de amistad y apoyo, y sexuales, de Lydia Cabrera fue definitiva su relación con una escritora refinada y cosmopolita como Teresa de la Parra y, sobre todo, su vida después junto a María Teresa de Rojas, conviviendo en una quinta habanera en donde intentaron recrear el mundo de la élite criolla de raigambre 
colonial, rodeadas de barriadas y poblaciones negras donde la magia y los rituales africanos andaban tan libres como los informantes que Lydia recibía, entrevistaba y grababa en su casa, apoyada, ayudada y alimentada por su compañera.

El grupo de mujeres en torno a Lydia Cabrera es fundamental como apoyo de su vida, pero también de su obra, incluso financieramente (Cuesta, 2015, pp. 17-21; Cámara, 2014). Gabriela Mistral tuvo un papel relevante en la primera edición de Cuentos Negros en Cuba y María Teresa de Rojas y Lydia Cabrera crearon un sello editorial, C \& R, con el que salieron impresos sus libros más importantes, tanto en Cuba como posteriormente en el exilio de Miami. En este caso, con un guiño muy característico, propio del humor y los saberes religiosos de Cabrera, la colección en la que se publicaron sus libros fue titulada "El Chicherekú en el exilio" porque:

"El Chicherekú es un muñeco de palo que construye el Ochono (el santero), insuflándole vida, y que manda de noche a hacer maldades [...] Los Orishas (dioses), se trasladaron al exilio con sus adoradores, sus Omó, sus hijos. ¿Por qué no iban a venir también los chicherekús?" (Hiriart, 1983, p. 92).

La solvencia económica de la familia de María Teresa fue en este sentido imprescindible para una Lydia Cabrera sin unas rentas ni una profesión remunerada. También Josefina Tarafa será una amiga fundamental. En su hacienda familiar en Matanzas Lydia Cabrera realizó su último trabajo de campo en Cuba. Un viaje memorable, en compañía de Pierre Verger, Alfred Metraux y otros, en el que se documentaron y fotografiaron las ceremonias dedicadas a Yemayá y la propia Josefina Tarafa fotografió y grabó, junto con Lydia, una gran cantidad de músicas y cantos religiosos que serían luego editados en Estados Unidos. Por su parte, las hermanas Amalia y María Helena Bacardí, amigas de juventud, subvencionaron la edición de varios de sus libros en Miami y en Madrid. En la edad ya avanzada de María Teresa y Lydia, la amistad y la colaboración de Isabel Castellanos, su albacea literaria, fue un sostén fundamental para el mantenimiento y el recuerdo de su obra.

De alguna manera, esta vida en femenino que representa una cultura oculta y solamente compartida por algunos grupos de "iniciadas", manteniendo una comunidad de apoyo mutuo segregada en el entorno de una sociedad hostil, puede verse como una forma similar a la vida cercana y observable, pero secreta y regida por sus propios códigos no comunes, que llevaban los negros de los barrios o los barracones cercanos a las casas blancas de las mujeres cubanas. Además del abordaje feminista de Edna M. RodriguezMangual (2004), la obra literaria de Lydia Cabrera ha sido objeto de otro interesante análisis desde la perspectiva de género por la investigadora canaria María Goretti Sánchez Morales (2016). También se ha puesto en relación su trabajo etnográfico con su orientación sexual en el sentido de que su atención hacia los grupos marginales y proscritos, y dentro de ellos, los que lo eran por su mundo ritual y mágico, aún más estigmatizado y esotérico, podría verse en correlación con la clandestinidad, la subalternidad, el silencio y la marginación que conlleva la condición de mujer homosexual (Cuesta, 2015, pp. 17-18).

La problemática identidad sexual de una mujer lesbiana en el ambiente burgués, heteropatriarcal e ideológicamente conservador en que vivía Lydia Cabrera consigue así un modo de expresión a través de la alteridad que le prestan sus santeros y sus ritos e idioma religioso. La espiritualidad y el mundo mítico de unas religiones sincréticas, en las que muchos actores, orishas o héroes de cuentos y leyendas tienen una gran labilidad en sus roles de género y de sexo, configuraron un lenguaje en el que la antropóloga pudo liberar y ver reflejadas sus propias experiencias y deseos. Así, Lydia Cabrera podía moverse y ser aceptada, en un contrapunteo continuo, en la hibridez de ser mujer y homosexual, de ser blanca entre los negros, de no creer en la religión y sin embargo servir sus obras de texto para los mayores adeptos. Dando voz a los negros descendientes de esclavos, siendo el canal a través del cual ellos pudieran expresarse; fluyendo con ellos, escamoteando su autoría, se sublimaba en estas otras voces, otros mensajes, otras experiencias, igualmente secretas e igualmente prohibidas por los blancos. De una forma propia, desde luego propia de las mujeres, Lydia Cabrera, con su ritmo contrapuntístico, consiguió no la emancipación del negro ni de las mujeres, pero sí transgredir profundamente el dominio hegemónico racial y de género en el que se había enculturado y en el que vivió toda su vida.

Un último contrapunteo aparece como muy relevante. Es el que tiene que ver con la identidad política, nacional e ideológica de Lydia Cabrera. El ambiente sociopolítico en el que se educó era el correspondiente a las élites blancas conservadoras de la República. Ella se desclasó de este ámbito de pertenencia, como hemos visto, en dos aspectos básicos y fundamentales: era una blanca que amaba a los negros y su magia; era una mujer que no se casó ni 
tuvo hijos y que vivió siempre con mujeres. Es decir, se desvió radicalmente del canon que debería haber encarnado y es indudable que fue estigmatizada por ello de manera consecuente. Pero aun quedaba un tercer marco del que salirse. Lydia Cabrera, tanto en su aspecto exterior, como en sus gustos culturales y sus hábitos de vida, era una mujer burguesa y criolla. Además de sus fotografías, hay numerosos párrafos de personas que la conocieron que destacan el aspecto pulido y la elegancia de ella y sus compañeras. Isabel Castellanos la retrata de nuevo:

"no solo no manejaba, Lydia no cargaba dinero; ella era como la reina de Inglaterra que no llevaba cartera. Ella no sabía lo que costaba nada" (Cámara, 2015, p. 28).

Su ideología política estuvo determinada por estos orígenes y no solamente conoció y defendió al dictador Gerardo Machado (García Vega, 1993, p. 55), sino que fue nombrada para determinados puestos técnicos de responsabilidad, como Asesora de la Junta del Instituto Nacional de Cultura, en los gobiernos de Batista. En 1955 recibe el encargo del montaje de una sala dedicada a la cultura afrocubana en el nuevo proyecto del Museo Nacional que se había inaugurado en La Habana en 1954 (Alonso González, 2018, pp. 51-56). Allí coincide con otra mujer, perteneciente a la misma élite cultivada, igualmente dedicada al estudio de las religiones afrocubanas, pero que seguirá un proceso ideológico contrario, de apoyo a la Revolución, Natalia Bolívar. Recuerda esta su trabajo inicial con Lydia Cabrera en el montaje de la sala del museo dedicada a los cultos religiosos, hecha en colaboración y con los materiales aportados por los informantes de Cabrera y también la contribución de Fernando Ortiz. El trabajo de Bolívar acabó en 1958, cuando fue encarcelada por el régimen de Batista (Bolívar, 2000, pp. 33-34), y el de Cabrera lo haría poco después, con el triunfo de la Revolución castrista, frente a la cual fue abierta y constantemente crítica y beligerante.

En parte su postergación y el olvido que ha sufrido su obra antropológica ha estado determinada por este posicionamiento político (Cámara, 2004-2005, p. 252); el mismo que le llevó a extrañarse de nuevo de su isla y de sus negros, y partir al exilio de Miami, sentido y descrito por ella como un "desierto de cemento", donde era imposible "atisbar el monte".

El exilio supuso para Lydia Cabrera y María Teresa de Rojas un desarraigo total y ambas tardaron mucho tiempo en reorganizar su vida. En el caso de Lydia esta desorganización afectó de modo fundamental a su trabajo, ya que, si bien consiguió llevar con ella su material y sus notas de trabajo de campo, no volvió a hacer etnografía entre los santeros que desarrollaron en Miami su culto y sus servicios de un modo adaptativo a las circunstancias del país de acogida. De hecho, según ella misma contó en una ocasión, estuvo sin escribir hasta que se instalaron en Madrid, donde vivieron dos años, antes de su vuelta definitiva a Miami (Hasson, 1987, p. 96). Tras diez años sin publicar nada de sus cuadernos de campo y ahogada en el páramo estéril de Miami, de nuevo Lydia Cabrera escarbó en los apuntes llevados con ella, en su pasado y en la memoria que sus negros guardaban del periodo colonial, del "tiempo España", y volvió a producir libros importantes, trayendo ese tiempo idealizado a un presente de ausencia y pérdida que ella identificaba con la dictadura castrista. La última etapa de su vida estuvo dominada por la necesidad de supervivencia fuera de su espacio-tiempo. Así, sus numerosos libros salieron con el mismo sello editorial C \& R creado en La Habana; siguió manteniendo a duras penas el contacto con algunos de sus amigos y babalawos que no habían salido de Cuba y, ya en su edad muy avanzada, consiguió el reconocimiento del mundo académico norteamericano, de la mano de William Bascom y otros antropólogos expertos en el Caribe y sus religiones. De hecho es gracias al Cuban Heritage Archive de la Universidad de Miami, que conserva y gestiona el fondo Lydia Cabrera Papers, como se puede acceder a una parte de la documentación generada por la antropóloga y escritora cubana.

Este último contrapunto de su vida tiene que ver con la contradicción política de mantener una ideología conservadora y eminentemente burguesa, en la cual habría que incluir además una cierta posición a favor de la presencia colonial española (García Vega, 1993, pp. 49-50), y a la vez dedicarse de un modo personal e intelectualmente empático a observar y transmitir la vida y las costumbres, no ya de los pobres o los subalternos, sino de los esclavizados; es decir, del límite más abyecto al que puede llegar el sistema capitalista. En el tiempo de los esclavos de Lydia Cabrera no aparecen las rupturas ni las contradicciones sociales. No hay desarraigo, sino continuidad de África; no hay dominación colonial, sino "tiempo España"; no hay República neocolonial, sino vida como libres en los barrios de las ciudades y en la manigua dominada por los espíritus, el lenguaje y la música ancestral; no hay revolución ni marxismo-leninismo, porque los negros, los ex esclavos, siguen con un tiempo y un devenir segregado e independiente de los momentos históricos, los acontecimientos y las evoluciones impuestas por el dominio de los blancos. 
Aquí tenemos la última contradicción, fértil y asumida, de Lydia Cabrera. La crítica cubana del interior la ha acusado de no haber podido superar sus prejuicios de clase burguesa al tratar los componentes africanos de la cultura nacional. Sin embargo, también se ha interpretado su obra -concretamente la hecha a partir de su exilio en Miami- como un "contrapunteo entre el cronotopo del mundo imaginado (Cuba durante la Colonia y la República hasta 1959) y el del tiempo de la escritura (en el exilio)" (Cairo, 2002, p. 83). En uno de sus libros de creación literaria, Itinerarios del insomnio. Trinidad de Cuba (1977), resulta clara esta conciencia de la autora de vivir en el presente de los muertos, rodeada de una memoria recreada, que ella misma no ha vivido.

Quizá fuera más adecuado pensar que el privilegiar un tiempo mítico, un pasado en el que el futuro es el presente -el presente de las leyendas míticas, los santos y las ceremonias- también tiene que ver con la construcción de una memoria colectiva diferencial para unas comunidades, como eran los diferentes grupos de africanos traídos como esclavos al Caribe, para las que los acontecimientos históricos tenían una lectura muy distinta a la de los occidentales. Lydia Cabrera se aferra a un "tiempo España" como a una infancia genérica, que también la incluye a ella, en la que árboles, espíritus, animales y gentes trasplantadas desde un origen africano, poblaron la manigua, creando una isla mitológica, de la que también ella era cómplice (Zambrano, 1950). Es decir, privilegiando el mito sobre la historia y la poesía sobre la barbarie.
Dejando aparte los prejuicios y reticencias ideológicas, la consecuencia es que en este contrapunteo que discurre entre la ciencia, los hechos positivos y concretos de la historia, en torno a los que se construyó una imagen y una práctica política dominante de lo que se consideraba la nación y la identidad de Cuba, por un lado, y la "antropoesía" de Lydia Cabrera y sus negros, por otro, el combate lo gana la visión objetivadora, masculina y clarificadora de Fernando Ortiz (Rodriguez-Mangual, 2004, pp. 40-41; Cámara, 2004-2005, p. 253). Pero ni la ideología política ni el poder de la ciencia académica han podido impedir que los libros de Lydia Cabrera -aún perseguidos, silenciados, secuestrados- hayan corrido hasta ahora de mano en mano entre los adeptos de las religiones afrocubanas y que en torno a ellos y su autora se haya fraguado una auténtica isla dentro de la isla: una isla negra en la más blanca de las islas del Caribe.

\section{AGRADECIMIENTOS}

Este trabajo se ha llevado a cabo formando parte del Proyecto Connected Worlds: The Caribbean, Origin of Modern World (ConnecCaribbean). Este Proyecto ha recibido fondos del programa de investigación e innovación Horizonte 2020 de la Unión Europea en virtud del acuerdo de subvención Maria Sklodowska-Curie № 823846. El Proyecto está dirigido por la profesora Consuelo Naranjo Orovio del Instituto de Historia-CSIC.

\section{BIBLIOGRAFÍA}

Alonso González, P. (2018). Cuban Cultural Heritage. A Rebel Past for a Revolutionary Nation. Gainesville: University Press of Florida. https://doi. org/10.2307/j.ctvx07534

Barreal, I. (1992). Prólogo. En Lachatañeré, R. El sistema religioso de los afrocubanos. La Habana: Editorial de Ciencias Sociales, pp. I-XXXVI.

Benítez Rojo, A. (1989). La isla que se repite. El Caribe y la perspectiva postmoderna. Hanover: Ediciones del Norte.

Benítez Rojo, A. (2003). Creolization and National Building in the Hispanic Caribbean. En Collier, G. y Fleischman, U. (eds.). A Pepper-Pot of Cultures: Aspects of Creolization in the Caribbean. Amsterdam: Rodopi, pp. 17-28. https://doi. org/10.1163/18757421-90000442
Bolívar, N. (2000). Tributo necesario a Lydia Cabrera y sus egguns. Catauro. Una revista cubana de antropología, I (1), pp. 29-35.

Cabrera, L. (1940). Cuentos negros de Cuba. La Habana: Imprenta La Verónica.

Cabrera, L. (1954). El Monte: igbo finda, ewe orisha, vititifinda (Notas sobre las religiones, la magia, las supersticiones y el folklore de los negros criollos y del pueblo de Cuba). La Habana: Ediciones C \& R.

Cabrera, L. (1973). La laguna sagrada de San Joaquín. Madrid: Ediciones Erre.

Cabrera, L. (1977). Itinerarios del insomnio. Trinidad de Cuba. Miami: Peninsular Printing Inc.

Cabrera Infante, G. (1996). Lydia Cabrera, antropoeta, prólogo. En Cabrera, L.
Cuentos negros de Cuba. Barcelona: Círculo de Lectores.

Cairo, A. (2002). Lydia Cabrera: praxis vanguardista y justicia cultural. Caminos, 24-25, pp. 73-83.

Cámara, M. (2004-2005). Las ceremonias del recuerdo: viaje a la laguna sagrada de Lydia Cabrera. Encuentro con la Cultura Cubana, 34-35, pp. 247-253.

Cámara, M. (2014). Sororidades habaneras entre María Zambrano y Lydia Cabrera. En Pumares-Alpizar, D. (ed.). El Atlántico como frontera. Madrid: Verbum, pp. 152-166.

Cámara, M. (2015). Para llegar a Lydia Cabrera. Conversaciones con Isabel Castellanos: las ceremonias del adiós entre Lydia Cabrera y María Teresa de Rojas. Revista Surco Sur, 5 (8), pp. 
28-30. https://doi.org/10.5038/21575231.5.8.22

Castellanos, I. e Inclán, J. (eds.). (1987). En torno a Lydia Cabrera (Cincuentenario de "Cuentos Negros de Cuba", 19361986). Miami: Ediciones Universal.

Castellanos, J. (2003). Pioneros de la etnografía afrocubana: Fernando Ortiz, Rómulo Lachatañeré, Lydia Cabrera. Miami: Ediciones Universal.

Cuesta, M. (2015). Lydia Cabrera entre amigas: Un tren de sores para una ciénaga cementada. Cuadernos Hispanoamericanos, 779. Monográfico Cuba en Miami (1959-2015), pp. 12-23.

Dianteill, E. y Swearingen, M. (2003). From Hierography to Ethnography and Back: Lydia Cabrera's Texts and the Written Tradition in Afro-Cuban Religions. Journal of American Folklore, 116, pp. 273-292. https://doi.org/10.1353/jaf.2003.0041

Duany, J. (2005). Reseña de 'Lydia Cabrera and the Construction of an Afro-Cuban Identity' de Edna M. Rodriguez-Mangual. Caribbean Studies, 33 (1), pp. 320-325.

García Vega, L. (1993). Entrevistando a Lydia Cabrera. En García Vega, L. Collages de un notario. Miami: La Torre de Papel, pp. 39-59.

Guillama Camba, R. (2019). Dos direcciones de un mismo camino: el hispanoamericanismo cultural de José María Chacón y Calvo.Naveg@mérica. Revista electrónica editada por la Asociación Española de Americanistas, 23. [En línea]. https://doi.org/10.6018/nav.397421
Gutiérrez, M. (1991). El cosmos de Lydia Cabrera: Dioses, animales y hombres. Miami: Ediciones Universal.

Hasson, L. (1987). Lydia Cabrera en Estados Unidos. En Castellanos, I. e Inclán, J. (eds.), En torno a Lydia Cabrera (Cincuentenario de "Cuentos Negros de Cuba", 1936-1986). Miami: Ediciones Universal, pp. 95-103.

Hiriart, R. (1980). Más cerca de Teresa de la Parra (diálogos con Lydia Cabrera). Caracas: Monte Ávila.

Hiriart, R. (1983). Lydia Cabrera: vida hecha arte (2.. ed.). Miami: Ediciones Universal.

Lagarde y de los Ríos, M. (2006). Pacto entre mujeres. Sororidad. Aportes para el debate, pp. 123-135. [En línea]. Disponible en: https://www.asociacionag. org.ar/pdfaportes/25/09.pdf

Le Riverend, J. (1991). Ortiz y sus contrapunteos. En Ortiz, F. Contrapunteo cubano del tabaco y el azúcar. La Habana: Editorial de Ciencias Sociales, pp. V-XXIX.

López, A. M. (2012). Unbecoming Blackness: The Diaspora Cultures of Afro-Cuban America. New York: New York University Press. https://doi.org/10.18574/ nyu/9780814765463.001.0001

Ortiz, F. (1940). Contrapunteo cubano del tabaco y el azúcar. La Habana: Jesús Montero.

Pérez, E. (2006). Lydia Cabrera and the Construction of an Afro-Cuban Cultural Identity. Journal of Latin American Anthropology, 11 (2), pp. 480-485. https://doi. org/10.1525/jlca.2006.11.2.480
Puig-Samper, M. A. y Naranjo, C. (2001). La acogida del exilio español en Cuba: Fernando Ortiz y la Institución Hispanocubana de Cultura. Ibero-Americana Pragensia. Suplementum, 9, pp. 199-213.

Rodriguez-Mangual, E. M. (2004). Lydia Cabrera and the Construction of an AfroCuban Cultural Identity. Chapel Hill: University of North Carolina Press.

Sánchez Morales, M. G. (2016). Diosas de ébano para Cuentos negros de Cuba de Lydia Cabrera. [Tesis doctoral inédita]. Las Palmas de Gran Canaria: Universidad de Las Palmas de Gran Canaria. [En línea]. Disponible en: https://accedacris.ulpgc.es/bitstre am/10553/18067/ 1/0726167_00000_0000.pdf

Santí, E. M. (2002). Fernando Ortiz: contrapunteo y transculturación. Madrid: Colibrí.

Toro, C. del (1996). Fernando Ortiz y la Hispanocubana de Cultura. La Habana: Fundación Fernando Ortiz.

Zalamea, F. (2000). Ariel y Arisbe: evolución y evaluación del concepto de América Latina en el siglo XX. Una visión crítica desde la lógica contemporánea y la arquitectónica pragmática de C. S. Pierce. Santa Fe de Bogotá: Convenio Andrés Bello.

Zambrano, M. (1950). Lydia Cabrera, poeta de la metamorfosis. Orígenes, 7 (25), pp. 11-15.

Zaramella, E. (2014). Una escucha al Contrapunteo latinoamericano de Fernando Ortiz. Caracol, 8, pp. 18-39. https:// doi.org/10.11606/issn.2317-9651. v1i8p18-39 